\title{
La función del nombre y sus cambios en la conformación de la identidad del héroe en Espejo de príncipes y caballeros de Diego Ortúñez de Calahorra ${ }^{1}$
}

\author{
The function of the name and its changes in the configuration of the hero's \\ identity in Diego Ortúñez de Calahorra's Espejo de príncipes y caballeros
}

\author{
Maribel Ayala Rodríguez \\ (Universidad Nacional Autónoma de México)
}

\begin{abstract}
RESUMEN
En diversas obras literarias el nombre de los personajes es un repositorio de elementos importantes para el desarrollo de la trama. En los libros de caballerías, además, el cambio de nombre es un recurso que destaca por su utilidad para marcar distintas etapas o aventuras en el desarrollo de los héroes. El Espejo de príncipes y caballeros de Diego Ortúñez de Calahorra (1555) es una excepción, pues su protagonista, el Cavallero del Febo, cambia de nombre una sola vez. No obstante, en esta historia tienen lugar conflictos que en otras obras son desencadenados típicamente por los cambios de nombre. Por ello, este artículo busca exponer los rasgos particulares del nombre del Cavallero del Febo y cómo éstos se relacionan con su identidad y le permiten prescindir del cambio de nombre sin afectar el desarrollo del libro de caballerías.
\end{abstract}

Palabras Clave

Caballero del Febo, onomástica, cambio de nombre, identidad, sobrenombres.

\begin{abstract}
In a variety of literary works the name of the characters is a repository of aspects that are important to the development of the plot. Besides, in romances of chivalry, the change of name is a highlighted resource because of its utility to mark different stages or adventures in the development of the heroes. The Espejo de príncipes y caballeros, by Diego Ortúñez de Calahorra (1555), is an exception, because its protagonist, the Cavallero del Febo, changes his name just once. However, in this story there are many conflicts that in other works are typically triggered by changes of name. As a result, this article aims to expose the particular features of the Cavallero del Febo's name and how those are relat-
\end{abstract}

1. Este trabajo expone, amplía y detalla parte de la investigación de mi tesis de licenciatura, presentada en enero de 2019 bajo la supervisión del Dr. Daniel Gutiérrez Trápaga, a quien agradezco sus observaciones para la elaboración del presente artículo. 
ed to his identity and allow him to dispense with change of name without affecting the development of the romance of chivalry.

KEYWORDS

Caballero del Febo, onomastic, change of name, identity, nicknames.

Recibido: 01/10/2019

Aceptado: 20/02/2020

En el género de los libros de caballerías, las obras suelen identificarse por los nombres de sus protagonistas. Aunque no es el único género en el que existe esta tendencia, estos nombres destacan por su excepcionalidad, ya que «no se corresponden con la realidad más cercana [...] sino que son exóticos, extravagantes y, en ocasiones, rimbombantes» (Coduras Bruna, 2015: 46). En la diégesis, a menudo estos apelativos son transformados o sustituidos por sobrenombres, algunas veces como consecuencia de una aventura, aunque también ocurre que son estos nuevos nombres los que dan pie a nuevas acciones. En uno u otro caso, el caballero siempre termina por retomar su nombre original, mientras que estos cambios quedan como un marcador de distintas fases en su identidad. Por ejemplo, en el Amadís de Gaula, Amadís es llamado Doncel del Mar a raíz de haber sido abandonado en el mar por Elisena. Eventualmente el héroe vuelve a ser llamado Amadís, pero «Doncel del Mar» remite a la etapa del héroe en la que fue criado por padres adoptivos, desconocía su linaje y no era un caballero todavía (Rodríguez de Montalvo, 1991: t. I, 253-326). Vistos de esta manera, los cambios de nombre resultan muy importantes, ya que el hilo narrativo de los libros de caballerías es precisamente la formación de la identidad del protagonista, es decir, los cambios que éste experimenta hasta consagrarse como el mejor caballero del mundo en los ámbitos amoroso, bélico y linajístico. Emilio José Sales Dasí señala la relación entre identidad y cambio de nombre en dos etapas del género:

Los caballeros intentan ocultar su verdadera identidad hasta realizar una serie de tareas por las que sea reconocido [sic]. En las primeras obras del género la adopción de un determinado sobrenombre obedece a una nueva etapa biográfica en la trayectoria del héroe: un suceso amoroso o personal interfiere en la progresión del individuo y determina la elección de un nuevo alias que tiene mucho que ver con los emblemas que figuren en sus armas nuevas [...]; sin embargo, conforme se suceden los textos cualquier circunstancia puntual da lugar a estos cambios en las armas y en el sobrenombre que devuelven al caballero otra vez al anonimato, hasta que vuelva a apropiarse de otra identidad caballeresca (2004:31).

En el Amadís, la primera obra del género, la dinámica entre nombre e identidad se aprecia en la gama de sobrenombres que recibe el protagonista conforme con sus aventuras a lo largo de su biografía: Amadís sin Tiempo, Doncel del Mar, Beltenebros, Caballero del Enano, Caballero Griego y Caballero de la Verde Espada (Rodríguez de Montalvo, 1991). Por citar un ejemplo más tardío, en la primera y segunda parte del Belianís de Grecia de 1547 el protagonista también recibe múltiples sobrenombres en distintas aventuras, entre ellos, Caballero de la Rica Figura, Caballero de las Ar- 
mas Jaldes, Caballero Sospechoso y Caballero de los Basiliscos (Fernández, 1997), aunque, como apunta Sales Dasí, estas denominaciones no se corresponden con etapas concretas de la biografía.

Muy diferente a los dos anteriores es el caso del Espejo de príncipes y caballeros de Diego Ortúñez de Calahorra (en adelante: Espejo I), libro de caballerías de 1555 que pertenece a lo que José Manuel Lucía Megías denomina paradigma de entretenimiento (1999: 25-32), pues el nombre del protagonista, el Cavallero del Febo, no cambia explícitamente más que una sola vez. Por ello, en este trabajo pretendo mostrar los rasgos particulares del nombre de este héroe, cómo éstos se relacionan con su identidad y le permiten evitar el uso de un sobrenombre en distintas aventuras. Los casos analizados incluyen aquellos en los que se esperaría un cambio nominal de acuerdo con el horizonte de expectativas del público creado por las primeras obras del género, principalmente por el Amadís, la obra fundacional del género. Por otra parte, se incluyen también aquellos casos en los que la misma narración demanda tal cambio, de modo que el análisis aporte nuevas perspectivas tanto al estudio del género como al de la obra en particular.

\section{Primeras consideraciones sobre el nombre del Cavallero del Febo}

Ortúñez de Calahorra no fue el primero en utilizar la fórmula «Espejo de...», que refiere a un género literario concreto (los espejos de príncipes), distinto a los libros de caballerías, para titular su obra, pues ya en 1525 había aparecido la primera parte del Espejo de caballerías de Pedro López de Santa Catalina, aunque esto no era lo común (Gómez Montero, 2001: 169). La mayoría de los títulos del género se componían por el nombre de pila del protagonista y un sintagma preposicional cuyo término de preposición, por lo general, se trataba de un topónimo, del lugar de origen de estos héroes, por ejemplo: Amadís de Gaula, Lisuarte de Grecia, o Palmerín de Inglaterra. Por otra parte, tanto los títulos apegados a este paradigma como el del Espejo I eran versiones acortadas de los verdaderos títulos, que solían contener otros detalles. La versión completa del nombre de la obra de Ortúñez de Calahorra era la siguiente:

Espejo de príncipes y cavalleros, en que se cuentan los inmortales hechos del Cavallero del Febo, y de su hermano Rosicler, hijos del grande emperador Trebacio. Con las altas cavallerías y muy estraños amores de la hermosíssima y estremada Princesa Claridiana, y de otros altos príncipes y cavalleros. Ahora nuevamente traduzido de latín en romance. Dirigido al muy illustre señor Don Martín Cortés, Marqués del Valle, por Diego Ortúñez de Calahorra, natural de la ciudad de Nágera (Ortúñez de Calahorra, 1975: vol. 1, 23).

Luego de la parte inicial que se conoce como el título, se escribe de manera explícita la intención de que el libro cuente las hazañas del Cavallero del Febo y de su hermano Rosicler, cuya relevancia se reduce de inmediato al ser presentado como hermano del primero. Cabe notar que el nombre de ninguno de estos héroes sigue la fórmula de nombre más sintagma preposicional, aunque el del Cavallero del Febo se asemeja. De hecho, esta obra llegó a tener como título alterno: El Cavallero del Febo. Daniel Eisenberg menciona que «Las únicas justificaciones que puede tener dicho nombre son que la licencia para la segunda parte cita el libro por este título, y que la traducción francesa (pero no la inglesa ni la italiana) lo emplea (Le Chevalier du Soleil)» (1975: vol. 1, XXX). Estas justificaciones podrían ser evidencia de que el nombre de la obra, poco a poco, en varios ámbitos, se fue asimilando a la forma paradigmática de los títulos del género, tomando el nombre del Cavallero del Febo y nunca el de Rosicler. 
La relación entre el Cavallero del Febo y Rosicler coincide con las relaciones fraternales de otros libros de caballerías en varios puntos. El aspecto gemelar está presente, por ejemplo, en el Florisel de Niquea de Feliciano de Silva con Anaxartes y Alastraxerea (Silva, 2015). Por otra parte, el uso del entrelazamiento para narrar los hechos del héroe y sus hermanos se ve desde el Amadís de Gaula, donde en los primeros libros se entrelazan las aventuras de Amadís con las de Galaor y Florestán. Según Juan Manuel Cacho Blecua, el entrelazamiento consiste en: «el relato de una, dos o más historias pertenecientes a personas diferentes y ocurridas en distintos espacios, en la mayoría de las ocasiones en tiempos simultáneos, contada-contadas ininterrumpidamente, para ser recogida-recogidas en la detención siguiente» (1986: 236). Esta estructura permite diversificar el texto y ofrece un contrapunto entre el protagonista y otros caballeros igualmente estimables, mientras que en otros textos, «A partir del entrelazamiento escritores como Feliciano de Silva consiguen ofrecer una perspectiva más plural de determinados motivos temáticos » (Lucía Megías y Sales Dasí, 2008: 130). El uso de esta técnica generalmente se limita a ciertas partes de las obras, pero no sucede así en el Espejo I, donde se mantiene hasta el final, como si de cierto modo el Cavallero del Febo no tuviera todo el protagonismo o necesitara, mucho más que sus congéneres, de su hermano para determinar su identidad. De hecho, es Rosicler quien lleva a cabo la búsqueda del linaje, esencial para la formación de la identidad del héroe. Con la existencia de este personaje, la ausencia de cambio de nombre parece menos notoria, pues la variedad que no agrega dicho cambio se sustituye con la aparición de un personaje completamente distinto.

Ya dentro de la estructura narrativa se desarrollan otros aspectos directamente relacionados con el nombre del protagonista. María Coduras Bruna señala que en los libros de caballerías ocurren tres eventos sobresalientes con respecto al nombre, los cuales denomina: impositio, mutatio y ocultatio (2015: 213). El primero en manifestarse es la impositio nominis, que refiere al momento en el que a los caballeros se les bautiza luego de nacer. Al ser gemelos, el Cavallero del Febo y Rosicler comparten este momento y sus nombres son asignados por la doncella de su madre, Clandestria, de acuerdo con las marcas con que cada uno nació: un sol y una rosa:

Y ansí el ama, echándoles agua por la cabeça, les dio el nombre del baptismo como mejor supo. Al que primero avía nascido llamó el Cavallero del Febo, por la figura que en él vido en el lado izquierdo, sobre el corazón. Y al segundo llamó Rosicler, por la rosa de los pechos. Desto huvo gran plazer la princessa, diziendo que les havía puesto los sobrenombres conformes a los que ellos merescían (Ortúñez de Calahorra, 1975: vol. 1, 93-94).

Los nombres motivados por estas marcas señalan además, implícitamente, la superioridad del Cavallero del Febo, sugerida ya de por sí por haber sido el primero en nacer. Según Luz Aurora Pimentel, un personaje referencial «remite a una clase de personajes que, por distintas razones, ha sido codificado por la tradición» (1998: 64). Dentro de esta clase se incluyen personajes históricos, mitológicos, alegóricos, tipos sociales, personajes literarios o asociados con algún género narrativo. En este caso, «Febo» proviene de la tradición clásica, como señala Eisenberg: «No cabe duda que Ortúñez conocía que Febo, nombre de Apolo, quería decir "sol" en griego» (1975: vol. 1, n. 4 y sigs., 93 $)^{2}$. La potencia que otorga esta referencia contrasta con la connotación de

2. Hay que recordar que en la cultura clásica el nombre de «Febo» puede referir a Apolo o a Helios, quienes a veces terminan asociándose. En las Metamorfosis, Ovidio «para referirse al Sol y a la Luna utiliza titán (el Sol es hijo de Hiperión, uno de los titanes) y Febe, el equivalente femenino de otro de los nombres del Sol, Febo; asimismo, estos dos últimos nombres son utilizados por Ovidio para Diana y Apolo». (Fernández Corte y Cantó Lorca, 2008: n. 7, 229). 
Rosicler, que además de relacionarse etimológicamente con la rosa, como palabra léxica coincide con el siguiente significado: «Dicho de un color: Rosa claro y suave, semejante al de la aurora» (DLE), es decir, que este personaje sería apenas un reflejo tenue de su hermano.

La narración se construye con el cuidado suficiente para lograr darle a Rosicler un lugar que, en principio, está a la altura de su hermano, a la vez que va marcando sutilmente la superioridad de éste. De hecho, implícitamente, por cómo se desarrolla la trama, se sabe que ni siquiera se trata de gemelos idénticos, lo que evita poner en duda la excepcionalidad del Cavallero del Febo, aunque, por lo demás, la presencia de Rosicler resulte útil para cubrir ciertas aventuras propias de los primeros libros de caballerías, como la devoción a una sola amada o la búsqueda del linaje, y dejarle espacio a su hermano para que se ocupe de otras hazañas bélicas y conflictos amorosos.

\section{Un nombre con varias lecturas}

El nombre del Cavallero del Febo tiene otras peculiaridades. Como se mencionó desde el principio, cada protagonista de los libros de caballerías tiene un nombre de pila original por el que se le reconoce dentro y fuera de la diégesis y que resuena por sí mismo mucho más que cualquier otro atributo o sobrenombre que llegue a poseer. En «Cavallero del Febo», la parte con mayor carga semántica parece ser «Febo», que contrasta con el de otros héroes como Amadís, Esplandián o Palmerín por su tradición clásica y porque nunca se usa sin «Cavallero», palabra que refiere a un título que estrictamente un recién nacido no podría obtener. Tanto es así que luego de su bautizo, durante los primeros años de su infancia en la corte de la princesa Briana, más tarde en la corte de Babilonia y hasta su ordenamiento caballeresco, ya no se le dice «Cavallero» sino «Donzel del Febo». La estructura de esta denominación puede reconocerse en la usada en el Amadís para el sobrenombre «Doncel del Mar», que el protagonista lleva mientras desconoce su linaje. El nombre «Cavallero del Febo», entonces, posee una estructura particular que Coduras Bruna identifica como una de las varias para crear sobrenombres:

[En el caso de la fórmula] Caballero + S. Adj. o S. Prep., el sobrenombre puede otorgarse o poseerse por diversas circunstancias $[. .$.$] :$

- El personaje desconoce su verdadero nombre y hasta el momento de su revelación porta un sobrenombre. Así ocurre con Amadís, el Doncel del Mar, o Amadís de Grecia, el Caballero de la Ardiente Espada.

- El caballero oculta voluntariamente su identidad y se bautiza o es bautizado por otros personajes con un sobrenombre temporal que responde a una amplia gama de características (armas, atributo, acompañante, comportamiento, hazaña, etc.). Ej.: Caballero Bermejo, Caballero del Vellocino Dorado, Caballero del Gigante, Caballero Acostumbrado a Siempre Vencer, etc. [...] (Coduras Bruna, 2015: 243-244) ${ }^{3}$.

Caballero + S. Adj. o S. Prep. es, entonces, una estructura bien asentada en el género que aparece en contextos de mutatio nominis, es decir, cuando algún caballero se ve en la necesidad de cambiar su nombre, y no en un contexto de impositio, como en este caso. Aún más, aparentemente la mutatio nominis está casi ausente en el Cavallero del Febo, a diferencia de un personaje como Amadís, cuya formación de identidad está marcada por constantes cambios en su apelativo. Para

3. Incluso Eisenberg señala la peculiar composición de este nombre de pila: «El Caballero del Febo se distingue por no tener otro nombre más que éste, acaso por ser tan colmado de virtudes caballerescas» (Eisenberg, 1975: vol 1, n. 4, 93). 
profundizar más en este contraste, es útil la siguiente observación acerca del nombre hecha desde la perspectiva narratológica:

\begin{abstract}
Además del mayor o menor grado de motivación en el nombre de un personaje es necesario que ese nombre tenga estabilidad y recurrencia, para poder asegurar no solo la coherencia y legibilidad del relato, sino la identidad misma del personaje y la conservación de la información narrativa que en torno a él se va generando. Si el nombre [...] se sometiera a constantes modificaciones [...], se perturbaría el principio de identidad del personaje, y por tanto su reconocimiento (Pimentel, 1998: 66).
\end{abstract}

En principio, esta postura no se ajusta a la poética de los libros de caballerías donde el héroe muda de nombre repetidas veces. No obstante, es distinto que un nombre no sea estable y recurrente, a que uno bien diferenciado sea sustituido temporalmente por un sobrenombre. Si bien ambos casos pueden tener el propósito general de ocultar la identidad, el desarrollo difiere: mientras que en el caso de un sobrenombre basta revelar el verdadero nombre para descubrir al personaje detrás, un nombre inestable y no recurrente puede no dar lugar al reconocimiento aunque, estrictamente, no se oculte nada. Pese a que en el Espejo I el héroe siempre es llamado textualmente «Cavallero del Febo», es posible que dentro de la diégesis no sea tan consistente.

Después de su impositio o bautismo, alrededor de los dos años de edad, el Cavallero/Donzel del Febo se separa del hogar materno, llevado por una pequeña barca hacia el mar, donde es rescatado por el príncipe Florión de Persia. El príncipe, al ver la marca de nacimiento del doncel y debido a que éste no fue capaz de comunicar su nombre, decide llamarlo Donzel del Febo, pero en otra lengua:

Y fue una cosa muy notable, que como no le supiessen el nombre que tenía, por causa de la maravillosa señal que tenía le pusieron nombre el Donzel del Febo, aunque por otras palabras ser en lengua pérsica, de manera que nombrándole de nuevo no lo mudaron el nombre que dantes tenía (Ortúñez de Calahorra, 1975: vol. 1, 131).

Esta no es la única parte del Espejo I en que la variedad lingüística se hace presente. Desde el prólogo aparece el tópico de la falsa traducción, es decir, la declaración de que el texto que está por narrarse es una traducción de textos previos en otro idioma. De acuerdo con Daniel Gutiérrez Trápaga «this hints at the intention of establishing a cycle, as multiple volumes allegedly remain to be translated» (2017: 123), es decir, que la existencia de fuentes ficticias cuyo contenido está restringido por el idioma abre la posibilidad de continuar el ciclo. De manera similar, como se verá a continuación, un nombre traducido en otra lengua abre la posibilidad de otros conflictos en la narración.

Coduras Bruna señala la problemática que suscita la traducción del nombre, ya que aceptarla supone «admitir que los NNPP [nombres propios] tienen un significado o categoría semántica y, por tanto, se pueden traducir $\gg$ (2015: 35). Por la naturaleza de las palabras que lo componen, en el caso del Cavallero/Donzel del Febo la traducción resulta completamente admisible, aunque nunca se llega a conocer la forma resultante, ya que en los libros de caballerías los cambios de lengua suelen narrarse pero no aparecer textualmente. Además, como se verá adelante, en la narración pocas veces se insiste en dicho cambio, por lo que podría pasarse por alto que el Cavallero/ Donzel del Febo tuvo algo parecido a una mutatio nominis al desplazarse de territorio. No obstante, 
pueden señalarse ciertas situaciones que sugieren que el resultado pudo ser lo suficientemente extraño para que, más tarde, sus familiares no lograran identificar al Cavallero del Febo con el niño perdido años atrás.

A los dieciséis años, el Donzel del Febo pasa a ser oficialmente el Cavallero del Febo (aún en lengua pérsica). En la corte de Babilonia, el doncel solicita recibir la orden de caballería, para lo cual, el sabio Lirgandeo le otorga unas armas, nada menos que con motivos y alusiones al sol:

[...] mandó desembolver dos líos que sus escuderos traían, y del uno sacó unas armas blancas, que parescían de fina plata, sembrados por ellas unos rayos de oro que descendían desde el yelmo, donde estava figurado un rostro muy hermoso y resplandesciente, que ansí parescía lançar de sí rayos como el sol, y con dificultad, con su bislumbre dexava ser mirado (Ortúñez de Calahorra, 1975: vol. 1, 163).

Sus prendas no otorgan elementos que impulsen un sobrenombre para la nueva etapa de su identidad, como sería, por ejemplo, el caso de Esplandián quien, debido a sus primeras armas, se hace llamar temporalmente Caballero Negro (Rodríguez de Montalvo, 1988: vol. 2, 1757; 2003: 133). La armadura del Cavallero del Febo antes bien refuerza la motivación del nombre al exteriorizar una marca que queda oculta bajo las vestiduras, así que la única alteración se da en la transición de doncel a caballero, palabras comunes que forman parte de su nombre propio:

Y tomando la rica espada del donzel desnuda en la mano, [el soldán de Babilonia] le dio tres golpes con él enzima del yelmo. Y después, metiendo la espada en la vaina, se la ciñó en la cinta, y le baxó la visera del yelmo, diziendo:

- Los altos dioses os tengan de su mano, que yo os armo cavallero.

$\mathrm{Y}$ aviendo primero jurado los capítulos que le pidieron para guardar y mantener la orden que le davan, besando la mano al soldán se levantó, quedando armado cavallero. [...]

Como el soldán y todos fuessen ya puestos en las ventanas y miradores, el Cavallero del Febo (que ansí le avían ya puesto), acompañado de los juezes y de otros muchos cavalleros, salió del gran palacio a la plaça (Ortúñez de Calahorra, 1975: vol. 1, 165-166).

La ceremonia se despacha rápidamente y después de su primera batalla y de recuperar Persia para el príncipe Florión, el caballero pretende regresar a Babilonia, el lugar donde se crió. Antes de partir, el sabio Lirgandeo le habla de la forma en que conocerá su linaje:

Y más os digo, de verdad, que jamás en vuestra vida haréis cosa de que tanto plazer recibáis como de las dos primeras que hiziéredes por dos cavalleros, los quales no conoceréis hasta quel tiempo, por su discurso os lo descubra. Y de vuestro linaje no quiero deziros cosa alguna, porque está ordenado ansí por los divinos dioses que de boca de uno destos dos cavalleros que te tengo dicho lo sepáis primero [...] (Ortúñez de Calahorra, 1975: vol. 1, 216)

El Cavallero del Febo no muestra interés por acelerar la búsqueda de sus orígenes, pero el destino lo guiará a encontrarse con su padre y luego con su hermano, sin que el reconocimiento suceda sino hasta más tarde.

Su siguiente aventura lo lleva hacia la ínsula de Lindaraxa, donde ésta tiene prisionero y encantado al emperador Trebacio, su padre. Una vez que el caballero logra rescatarlo, se presenta: «Yo 
me llamo el Cavallero del Febo, y no sé de qué tierra me soy más de que fui criado en Babilonia. A lo que me han dicho, siendo niño fui hallado en la mar» (Ortúñez de Calahorra, 1975: vol. 2, 205). En este punto, como consecuencia de su secuestro, Trebacio desconoce que tiene dos hijos, por lo que lógicamente el nombre no le dice nada. Por otra parte, la comunicación entre los caballeros es inmediata, sin reparo en la barrera lingüística, pese a que el Cavallero del Febo sí menciona su crianza en Babilonia. Bajo ciertas circunstancias, dicha naturalidad comunicativa pasaría a formar parte del pacto de lectura con el género, ya que:

El caballero por lo general se desplaza casi libremente por los espacios geográficos y visita diferentes reinos, sin que el autor se detenga a mencionar que la diferencia de idioma sea un problema. Podría decirse que o bien no es relevante para el desarrollo de la acción, o bien el héroe, por ser quien es y como es, no enfrenta ese obstáculo (Campos García Rojas, 2005: 488-489).

No obstante, el idioma en este caso no parece tan irrelevante para el desarrollo de la trama. Quien habla una lengua extranjera y lleva un nombre en dicha lengua es el propio protagonista. Más adelante se narra una posible huella de las consecuencias de esta diferencia lingüística. Al reunirse con la princesa Briana, ésta le informa a Trebacio todo lo sucedido durante su ausencia:

Y ansí, con alguna vergüença le dijo que avía quedado preñada, y avía parido dos hijos con el grande estremo de su hermosura, y maravillosas señales de sus cuerpos. Y ansí mesmo le dixo, no sin algunas lágrimas que por su rostro destilava, la manera en que el Donzel del Febo se avía perdido (Ortúñez de Calahorra, 1975: vol. 2, 293-294).

Esta información se presenta en discurso indirecto y por lo tanto no es posible conocer los datos exactos que posee Trebacio. Sin embargo, en el caso de que Briana sí hubiera revelado el nombre del hijo perdido, podría apuntarse a dos ideas: que el nombre en lengua pérsica era lo suficientemente irreconocible, o bien, que Trebacio pensara que el nombre de su amigo, el Cavallero del Febo, era un sobrenombre motivado por la imagen del sol en sus armas y que no tenía nada que ver con el nombre de su hijo.

El siguiente encuentro del Cavallero del Febo es con Rosicler. Éste se halla solo en la isla del gigante Candramarte, quien le ha tendido una trampa para cobrar venganza por haberle cortado los brazos. El Cavallero del Febo llega, lo socorre y, tras vencer al gigante y a todos sus caballeros, los hermanos se presentan:

- [...] sabed que yo he nombre el Cavallero del Febo, por la devisa del sol que traigo en estas armas. Otra cosa no podré deziros por dónde de mí podáis aver mayor noticia, porque de verdad os digo que nunca otra cosa supe de mi hazienda. [...].

Entre tanto questo dezía el Cavallero del Febo, Rosicler, muy atento y suspenso lo estava mirando. Y como le oyesse dezir que se llamaba el Cavallero del Febo, y que no sabía otra cosa de su hazienda, no dexó de pensar en su coraçón si por ventura sería aquél su hermano el Donzel del Febo, de quien tantas maravillas el sabio Artemidoro avía dicho. Y

\footnotetext{
4. Un ejemplo en el que se muestra explícitamente una diferencia lingüística que afecta el desarrollo de la narración es el de Palmerín en tierra de moros: «El moro no lo entendió mas bien conoció que era cristiano en su lenguaje, e dixo: -Tú veniste a buscar tu mal, que conmigo yrás cautivo, que yo conozco que eres cristiano» (Palmerín, 2004: 164). Para un análisis más detallado de este caso, véase Rubio Pacho (2013).
} 
dexando esta sorpresa para preguntarle después algunas cosas más despacio, respondiendo a lo que le avía dicho, le dixo:

- [...] Mi nombre sabed que es Rosicler, y solía ser cavallero en la corte del rey Oliverio de la gran Bretaña, aunque ya mis tristes hados y mi mala fortuna me ha traído a tal tiempo que aun mi nombre no es digno de ser oído en aquella tierra. (Ortúñez de Calahorra, 1975: vol. 2, 122-126).

Rosicler, quien posee más información acerca de su familia y ha salido del hogar materno con el objetivo de reunirla, sospecha que está frente a su hermano, pero antes de poder indagar más, otro batel se lleva al Cavallero del Febo hacia otra aventura. En este caso, el problema de la barrera lingüística parece menos probable, ya que justamente es el nombre lo que levanta sospechas en Rosicler. Según el texto, la única diferencia que nota Rosicler es el uso de «Cavallero» en vez de «Donzel». Por otra parte, el Cavallero del Febo dice que tal nombre está motivado por sus armas, sin mencionar su marca de nacimiento, lo cual acentúa la duda de Rosicler, pues cualquiera que poseyera tales armas podría adoptar con toda probabilidad ese sobrenombre.

Rosicler tarda en descubrir que, en efecto, su aliado en la ínsula de Candramarte era su hermano. Luego de descifrar todos los enredos de su familia, se dirige a Constantinopla con el nombre de Cavallero de Cupido con la intención de enfrentarse con el Cavallero del Carro para probar su valía y darse a conocer a sus padres, sin saber que este caballero es en realidad su hermano con un sobrenombre que ha adoptado a raíz de la aventura de Meridián y Lindabrides.

\section{La breve mutatio nominis}

Meridián y Lindabrides son hermanos gemelos que se disputan la herencia del trono de Tartaria. Para resolver su conflicto, viajan en un carro en busca de un caballero que quiera pelear contra Meridián y ganar el trono para Lindabrides. El Cavallero del Febo, enamorado de la dama, pelea y gana, pero para consolidar su victoria debe ir a Constantinopla a defender la belleza de Lindabrides. Para ello, Meridián, quien de buena gana acepta su derrota, le ofrece sus armas y el carro en el que viajan:

el príncipe Meridián descubrió al valeroso Cavallero del Febo el grande y entrañable amor que tenía a la hermosa infanta Floralindia, hija del grande rey de Macedonia. Y más, le dixo que él tenía en voluntad de ir a la corte del rey y estar ahí unos días desconoscido, para lo qual le rogó que le diesse sus armas y cavallo, y que él le daría las suyas y el su cavallo Cornerino, con las quales podría ir desconoscido o disfraçado a las grandes fiestas que se hazían en la corte del grande emperador Trebacio, donde havía de estar los dos meses defendiendo la hermosura de la infanta Lindabrides su hermana (Ortúñez de Calahorra, 1975: vol. 3, 200).

Esta es la primera y única ocasión en que el caballero tiene, sin lugar a dudas, un caso de mutatio nominis ya que, como sugiere el príncipe Meridián, a ambos les convenía el anonimato por ser mantenedores de un paso. Coduras Bruna señala la relación entre armas, ocultamiento del nombre y conveniencia:

Dependiendo de la situación en que se encuentre, es preferible que [el caballero] oculte su verdadera identidad. Así, la ocultación del nombre, y normalmente su sustitución por 
un sobrenombre, suele ir acompañada por un cambio de armas que impide la identificación del personaje, dado que estas, su color o el emblema del escudo, junto con el nombre propio, conforman otro de los principales rasgos identificativos de los caballeros, pues las armas y otros soportes como la vestimenta están asociados a la onomástica. (Coduras Bruna, 2015: 222).

En la trama, esta mutatio nominis tiene efectos en la identidad del protagonista en los aspectos amoroso y linajístico.

Además de la practicidad del nuevo sobrenombre del caballero, éste tiene también un sentido más simbólico, ya que «En ocasiones, los personajes que acompañan a los caballeros o a los que se deben sugieren su nombre (Caballero del Enano, Caballero de la Duquesa, Caballero del Gigante) $\gg$ (Coduras Bruna, 2015: 247). En este caso, el caballero toma su nombre de la parafernalia que ostenta, que ha tomado a raíz de pelear por Lindabrides y que ahora le sirve para defender la hermosura de ésta, de modo que el Cavallero del Carro pasa a ser, por una suerte de metonimia, el caballero de Lindabrides. Sin embargo, al igual que el amor hacia esta dama, este nombre tampoco perdura, pues de acuerdo con María Carmen Marín Pina «el nombre se considera definición de la persona y por ello siempre que el caballero cambie de estado y de sentimientos lo modificará. La onomástica también concuerda en este sentido con el curso de sus amores» (1990: 174). Tras un buen número de combates en la corte de Constantinopla, llega un caballero anónimo a quien no logra vencer. A mitad del encuentro, un enano se dirige a ambos contrincantes con las siguientes palabras:

Y assí, se fue derecho para el Cavallero del Febo, y dándole una lança, le dixo:

- Esta lança os envía un sabio que os dessea mucho servir, para que justéis con ella con este cavallero que teneis delante. Y os haze saber que haréis con ella un tal encuentro que la fuerça dél será buelta toda contra vos, y passará por medio el vuestro grande y fuerte coraçón. Y primero os acabará la muerte que podáis sanar de tal herida.

Y como esto dixo, el Cavallero del Febo le tomó la lança, muy maravillado de las palabras que le avía dicho. Y sin más le dezir, se partió el enano dél, y yéndose para el cavallero estraño, le dio la otra lança que llevava, y le dixo:

- Esta lança os envía un sabio para que justéis con el Cavallero del Carro, y os haze saber que de este encuentro venceréis a vuestro contrario, y le haréis que pierda el nombre que aora tiene, aunque vos quedaréis herido para siempre (Ortúñez de Calahorra, 1975: vol. $3,255-256)$.

Al golpear las lanzas, ambos caballeros son despojados de su yelmo, revelándose así sus respectivas identidades. Mientras el Cavallero del Febo es reconocido por Trebacio, el adversario se revela como una virgo bellatrix: Claridiana, hija del emperador de Trapisonda (Marín Pina, 1989: $82)^{5}$. El resultado del enfrentamiento es un empate, lo que permite al Cavallero del Febo seguir combatiendo contra otros caballeros. Por otra parte, de acuerdo con el sentido de la profecía, Claridiana obtiene la victoria, dado que ha revelado la identidad del Cavallero del Febo, lo que le otorga cierto poder sobre él: «Conocer el nombre del personaje supone ejercer cierto dominio

5. Utilizo el término «virgo bellatrix», ya que Marín Pina señala dos variantes de este tipo de personaje: «la doncella guerrera, la doncella que por circunstancias diversas viste los hábitos de caballero y, encubriendo su propio sexo, practica accidentalmente la caballería, en oposición a la amazona, otra variante del arquetipo de la mujer belicosa, guerrera por naturaleza y educación e inicialmente andrófoba» (1989: 82). Claridiana se encuentra entre las dos variantes, ya que si bien debe su condición a su educación como hija de la reina de las amazonas, el ámbito amoroso también repercute en su caracterización. 
sobre él, por ello muchas veces los caballeros guardan celosamente el suyo y su encubrimiento provoca discusiones y enfrentamientos de fuerte tensión narrativa» (Marín Pina, 1990: 175). En este caso, el Cavallero del Carro, quien estaba consagrado al amor de Lindabrides, torna a ser el Cavallero del Febo, no sólo por haber perdido el yelmo, sino por quedar prendado de Claridiana al perder también ella su yelmo:

[esta real princesa] con su celestial y hermosa vista a todos quantos avía en la gran plaça puso en grande y muy estraña admiración, y los dexó atónitos y suspensos, no creyendo que fuesse visión menos que divina. De donde no con mucha razón la hermosa infanta Lindabrides al su Cavallero del Febo podrá culpar si, herido de tan fuerte y poderoso golpe, alguna parte del grande y verdadero amor que le tenía se le turbó. Porque sin ser parte para resistirlo, se le partió por medio el coraçón, y la una parte quedó con las viejas y profundas raízes que solía, y la otra la entregó a aquella soberana princessa que tenía delante (Ortúñez de Calahorra, 1975: vol. 3, 257).

El sobrenombre «Cavallero del Carro» pierde su sentido simbólico, pues ya no es más el caballero de Lindabrides, pero sobre todo, al recuperar su nombre anterior, lo hace con un nuevo significado. El momento previo a la revelación de los rostros ocurre en un momento particular del día en que los astros toman una determinada posición:

Y tornándose luego a endereçar, a la salida del resplandeciente Febo y de la hermosa Diana, quando suele salir más clara, paresció la vista de los rostros de aquellos cavalleros. Porque el Cavallero del Febo mostró aquel severísismo y perfecto rostro, que asta entonces ninguno de los que avía en la plaça lo avían visto. Y por otra parte, el cavallero estraño paresció ser aquella soberana y sin par en hermosura Claridiana [...] (Ortúñez de Calahorra, 1975: vol. 3, 256-257)

El nombre otorgado en la impositio nominis ya no está ligado únicamente a la marca de nacimiento o a la superioridad frente a Rosicler, sino que resulta complementario con una parte del nombre de Claridiana, pues los nombres remiten a los nombres clásicos del sol y la luna: Febo y Diana, lo cual sugiere que, eventualmente, el caballero será identificado como el amante de esta virgo bellatrix y ya no de Lindabrides. Esto genera un conflicto amoroso que se desarrolla y resuelve en la segunda mitad del Espejo I, luego de que el Cavallero del Febo recupera su linaje.

Mientras tanto, tras la justa contra Claridiana, el Cavallero del Febo se reúne con el emperador Trebacio y conoce a la emperatriz Briana. Al igual que Rosicler al encontrarse por primera vez ante su hermano, Briana considera, sin mucha esperanza, la posibilidad de que se trate de su hijo:

Y de allí recibió la emperatriz al Cavallero del Febo. Que como él se pusiesse delante della para le besar las manos, la emperatriz lo levantó por la mano. Y como le pareciesse mucho a su hijo Rosicler, assí en el aire y semblante del rostro como en su dispusición, las lágrimas se le vinieron a los ojos, acordándose de sus perdidos hijos. Y dando un gran sospiro, dixo entre sí: $\ll_{i} \mathrm{O}$ si me hubiera hecho Dios a mí tan gran merced que fuera este cavallero alguno de mis hijos!» (Ortúñez de Calahorra, 1975: vol. 3, 260).

A pesar de que Briana conoce el nombre del caballero y nota el parecido con Rosicler, la anagnórisis no sucede. Enseguida, bajo el nombre de Cavallero de Cupido, Rosicler llega a la corte de Constantinopla, rehusándose a revelar su identidad ante sus padres si no vence antes al Cavallero 
del Carro. Rosicler sabe que el Cavallero del Febo es su hermano, pero no tiene noticia de las nuevas armas y sobrenombre que porta, por lo que la tensión aumenta hasta que ambos caballeros se encuentran a punto de morir peleando el uno contra el otro. Según Marín Pina, los caballeros, «Al negarse a descubrir su identidad [...] se enfrentan con sus hermanos o progenitores sin que la llamada de la sangre sirva en este caso para alertarlos, etc. Sólo el lector posee en tales casos la clave para deshacer los enredos y los equívocos surgidos» (1990: 175).

Los caballeros mantienen el duelo durante ocho horas, al final de las cuales quedan inconscientes, por lo que Rosicler no puede revelar lo que sabe y la anagnórisis vuelve a dilatarse. Los dos heridos son llevados al castillo de los emperadores y, al despertar, ambos lloran su derrota en su respectivo lecho, de modo que el Cavallero del Febo escucha los lamentos de Rosicler y al fin se reconocen:

- O mi señor y grande amigo Rosicler [...]. Veis aquí al vuestro cavallero del Febo, aquel que en la ínsula del falso gigante, [...] en el hermoso y ligero batel perdistes. Veisme aquí que yo soy esse mesmo Cavallero del Carro con quien el día passado la peligrosa y fuerte batalla hezistes [...] Mirad, señor, si alguna cosa de mis padres vos sabéis, no me lo queráis negar. Catá que yo soy el Cavallero del Febo. Y porque seáis más cierto de lo que digo, veis aquí esta señal que en el cuerpo tengo [...]

[Rosicler] dezía:

- [...] O mi señor Cavallero del Febo, ¡conosce al vuestro Cavallero de Cupido! Que es aquel Rosicler que vos, yendo en el pequeño batel, en la ínsula del gigante librasteis de muerte. Porque aunque yo tan alta magestad no pueda merecer, os hago saber que soy vuestro hermano, nascidos entrambos en un tiempo y de un mesmo vientre, de la alta y soberana emperatriz Briana al tiempo que en el Monesterio de la Ribera de nuestro soberano padre el emperador Trebacio quedó preñada. [...] (Ortúñez de Calahorra, 1975: vol. 3, 294-295).

Por primera vez el Cavallero del Febo utiliza su marca de nacimiento y no sus armas como evidencia de su nombre y manifiesta deseos por conocer su linaje. Briana y Trebacio se unen al cuadro y toda la tensión acumulada se libera. Así, el uso del sobrenombre «Cavallero del Carro», que ya había sido eliminado casi completamente desde el encuentro con Claridiana, concluye definitivamente, como si junto con el sobrenombre de Rosicler, «Cavallero de Cupido», hubiera sido creado con el objetivo de provocar una batalla intrafamiliar y prolongar así la espera y la tensión de la anagnórisis. Para este punto en el que Rosicler tenía la mayor parte de las piezas necesarias para reunir a su familia, la inestabilidad del nombre del Cavallero del Febo ya no bastaba por sí misma para dar lugar a dudas y enredos, sino que hacía falta una verdadera mutatio nominis, que de paso era útil para marcar la transición del caballero en el ámbito amoroso.

\section{La fijación del nombre}

La identidad del Cavallero del Febo no deja de transformarse en este punto. Luego de conocer a su familia sucede también su conversión al cristianismo (Ortúñez de Calahorra, 1975: vol. 4, 11). Este evento no conlleva ninguna mutatio nominis, por el contrario, el nombre se vuelve mucho más estable, pues la religión lo reintegra completamente a su linaje. No obstante, su triángulo amoroso todavía no está del todo resuelto. 
Luego de haberle declarado su amor a Claridiana, el Cavallero del Febo tiene un momento en el que vuelve a inclinarse por Lindabrides. En venganza, Claridiana oculta su identidad y se enfrenta a él en un combate. Cuando el Cavallero del Febo descubre que ha justado con su amada y que ésta le guarda rencor, como penitencia, se destierra a la Ínsula Solitaria, donde pelea contra el endemoniado fauno, pero sin dos de sus atributos más característicos: su caballo y su espada (Ortúñez de Calahorra, 1975: vol. 5, 145-173). Luego de vencer al monstruo de la isla, el caballero queda en soledad y se entrega a un estado de salvajismo, lo cual implica una pérdida de su nombre, puesto que no hay nadie que pueda enunciarlo. Es decir, que en lugar de un cambio de nombre, como cuando Amadís se convierte en Beltenebros al ser rechazado por Oriana (Rodríguez de Montalvo, 1991: t. I, 709), aquí «Cavallero del Febo» simplemente se diluye y pierde la solidez que parecía haber adquirido tras la recuperación del linaje del héroe. La penitencia amorosa dura hasta que Claridiana lo encuentra:

Después que uvieron comido, el buen cavallo Cornerino andava por allí con el de la princessa, y luego el Cavallero del Febo con una gran voz lo llamó, y el cavallo se vino para él, que ansí lo tenía por costumbre de hazer. Y después que lo hubo tomado, luego se dexó tomar el de la princessa. Y queriendo ya salir de allí, los dos, travados de las manos, se vinieron hasta que llegaron donde el Cavallero del Febo avía dexado sus buenas armas, adonde se armó dellas, ayudándole la princessa [...] (Ortúñez de Calahorra, 1975: vol. $5,327)^{6}$.

Además de perdonarlo, Claridiana devuelve al caballero sus armas y su nombre, pues como señala Rosario Aguilar Perdomo: «solamente una muestra de amor por parte de sus señoras podrá arrancar a los héroes de su melancolía y la desesperación en que están abatidos, reintegrarlos a la vida cortesana con su antigua identidad y dar por terminadas sus penitencias» (2001: 148). Así, con la culminación de este pasaje el nombre de «Cavallero del Febo» vuelve a identificar al héroe con sus hazañas y su linaje, a la vez que refuerza su vínculo con su amada Claridiana.

\section{Conclusiones}

En el Espejo de príncipes y cavalleros I la multiplicidad de aventuras y los cambios en la identidad se manifiestan sin recurrir al cambio de nombre como ocurre en los libros de caballerías fundacionales e incluso en obras contemporáneas al Espejo I: en primer lugar, existe un personaje inusual, el gemelo Rosicler, cuyo nombre lo coloca en un nivel de importancia inferior al de su hermano. Sin embargo, entre sus hechos y atributos destacan dos que corresponden a la expectativa de un protagonista caballeresco de los inicios del género: ser fiel a una sola amada y llevar a cabo la búsqueda de su linaje. Mientras Rosicler cumple estas funciones, el verdadero protagonista, el Cavallero del Febo, logra tener un desarrollo con mayor libertad en el ámbito amoroso al tener dos amadas y varias aventuras ligadas a ellas, mientras que nunca se ocupa de la búsqueda de su linaje.

6. Este pasaje es muy significativo en términos de la recuperación de la identidad, ya que se enuncian los elementos que hacen que el caballero abandone su estado salvaje. Según Ana María Morales «el hombre medieval necesita de la sociedad para definirse, y así, una vez que los dementes entran en contacto con algún representante de esa sociedad -el ermitaño, una doncella, algún caballero-, éste lo primero que les proporciona es un nexo con el mundo al cual deben regresar: el pan o los vestidos» (1991: 22). En el Amadís el inicio de la reintegración del héroe al mundo civilizado ocurre gracias al ermitaño, aunque la identidad se recupere del todo solamente con el perdón de Oriana. En el Espejo I, todos esos elementos quedan en manos de Claridiana. 
Aunado a lo anterior, el nombre «Cavallero del Febo» ofrece varias posibilidades narrativas. Por una parte, otorga a su portador dos características que lo señalan como el protagonista: el título nobiliario de caballería y la alusión a su marca de nacimiento, la cual le confiere superioridad frente a Rosicler y determina el vínculo amoroso con Claridiana. Por otra parte, el nombre parece confuso dentro del mundo ficticio, pues muchas veces distintos personajes tienen dificultades para descubrir al personaje detrás del nombre «Cavallero del Febo». Si bien se carece de elementos contundentes que revelen las verdaderas causas que en cada caso obstaculizan dicha identificación, pueden señalarse algunas posibilidades: la primera es el cambio de lengua en el nombre (pasa de castellano a pérsico), la segunda, la variación de estatus (el personaje pasa de doncel a caballero) y la tercera es que la estructura de dicho nombre es confundible con la de un sobrenombre (Caballero + S. Adj. o S. Prep.). En cualquier caso, ninguno de estos aspectos parece haber dado lugar a una contradicción que fuera en detrimento de la obra, pues las confusiones se aceptan como parte del universo narrativo. Así, tanto la existencia de Rosicler como las características del nombre «Caballero del Febo» se aprovechan narrativamente para suscitar tantos equívocos como el uso de un sobrenombre, sin necesidad de ampliar la lista onomástica.

Por último, es importante señalar el potencial del estudio de los cambios de nombre en todo el ciclo del Espejo de príncipes y caballeros. Ya que por lo menos en lo que respecta a las continuaciones escritas por Pedro de la Sierra y Marcos Martínez no hay un relevo generacional, sino que se continúa en gran medida con las aventuras de los protagonistas de la primera parte, existe la posibilidad de profundizar en los cambios de nombre del Cavallero del Febo, así como de otros personajes importantes, como Trebacio y Rosicler. La realización de dicho trabajo aportaría nuevas perspectivas al estudio de cada una de las obras, del ciclo entero y su evolución, así como de la influencia que éste marcó en obras posteriores.

\section{Bibliografía}

Aguilar Perdomo, María del Rosario (2001), «La penitencia de amor caballeresca: Lisuarte, Florambel, Felixmarte y otros enfermos de amor», en Fechos antiguos que los cavalleros en armas pasaron. Estudios sobre la ficción caballeresca, ed. Julián Acebrón Ruiz, Lleida, Ediciones de la Universidad de Lleida ('Ensayos/Scriptura'), pp. 125-149.

Cacho Blecua, Juan Manuel (1986), «El entrelazamiento en el Amadís y en las Sergas de Esplandián», en Studia in Honorem prof. M. de Riquer, Barcelona, Quaderns Crema, vol. I, pp. 235-271.

CAmpos García Rojas, Axayácatl (2005), «Las lenguas extranjeras en los libros de caballerías: Amadís de Gaula y las Sergas de Esplandián», en Actes del X Congrés Internacional de l'Associació Hispànica de Literatura Medieval, Alicante, Institut Interuniversitari de Filologia Valenciana, pp. 487-497.

Coduras Bruna, María (2015), Por el nombre se conoce al hombre. Estudio de antroponimia caballeresca, Zaragoza, Prensas de la Universidad de Zaragoza ('Colección Humanidades').

Corbera, Esteban (2005), Febo el Troyano, ed. José Julio Martín Romero, Alcalá de Henares, Centro de Estudios Cervantinos ('Los libros de Rocinante', 20).

Di Stefano, Giuseppe (Ed.) (2004), Palmerín de Olivia (Salamanca [Juan de Porras], 1511), Alcalá de Henares, Centro de Estudios Cervantinos ('Los libros de Rocinante', 18). 
DLE: Diccionario de la lengua española (Madrid: Real Academia Española) [Consulta 29-102018].

EISEnBeRG, Daniel (1975), «Introducción» en Diego Ortúñez de Calahorra, Espejo de príncipes y cavalleros o El cavallero del Febo, Madrid, Espasa-Calpe ('Clásicos Castellanos'), t. 1, 6 tt., pp. XVII-LXXXVIII.

FERNÁNDEZ, Jerónimo (1997), Hystoria del magnánimo, valiente e inuencible cauallero don Belianís de Grecia, ed. Lilia E. F. De Orduna, Kassel, Edition Reichenberger, ('Ediciones Críticas', 84 y $85), 2 \mathrm{tt}$.

Gómez Montero, Javier (2001), «Espejo de Caballerías (libro I) de Pedro López de Santa Catalina (1525)», en Antología de libros de caballerías castellano, coord. José Manuel Lucía Megías, Alcalá de Henares, Centro de Estudios Cervantinos, pp. 169-174.

Gutiérez Trápaga, Daniel (2017), Rewritings, Sequels, and Cycles in Sixteenth- Century Castilian Romances of Chivalry. 'Aquella Inacabable Aventura', Woodbridge, Támesis.

Lucía Megías, José Manuel (1999), «Libros de caballerías castellanos: textos y contextos», en Edad de Oro, Universidad Autónoma de Madrid, Madrid, vol. XXI, pp. 9-60.

y Emilio José Sales Dasí (2008), Libros de caballerías castellanos (siglos XVI y XVII), Madrid, Laberinto ('Colección Arcadia de las Letras').

MARín PinA, María Carmen (1989), «La aproximación al tema de la virgo bellatrix en los libros de caballerías españoles $\gg$, Criticón, 45, pp. 81-94.

(1990), «El personaje y la retórica del nombre propio en los libros de caballerías españoles», Tropelías: Revista de Teoría de la Literatura y de Literatura Comparada, I, pp. 165-175.

Morales, Ana María (1991), «El loco salvaje de la literatura artúrica», en Anuario de Letras Modernas, México, Universidad Nacional Autónoma de México, Facultad de Filosofía y Letras, vol. V, pp. 11-23.

OrtúñEZ de CalahorRa, Diego (1975), Espejo de príncipes y cavalleros o El cavallero del Febo, ed. Daniel Eisenberg, Madrid, Espasa-Calpe ('Clásicos Castellanos'), $6 \mathrm{tt}$.

Ovidio (2008), Metamorfosis, trad., introd. y notas José Carlos Fernández Corte y Josefa Cantó Llorca, Madrid, Gredos ('Biblioteca Clásica Gredos', 365).

Pimentel, Luz Aurora (1998), El relato en perspectiva, Ciudad de México, Universidad Autónoma de México, Siglo XXI.

Rodríguez de Montalvo, Garci (1988), Amadís de Gaula, ed. Juan Manuel Cacho Blecua, Madrid, Cátedra, 2 vols.

(2003), Las sergas de Esplandián, ed. Carlos Sainz de la Maza, Madrid, Castalia.

Silva, Feliciano de (2015), Florisel de Niquea, partes I-II, ed. Linda Pellegrino, Alcalá de Henares, Universidad de Alcalá.

Rubio Pacho, Carlos Alberto (2013), «"Acordó de fazerse mudo e jamás hablar”: Palmerín entre moros», en Palmerín y sus libros: 500 años, eds. Aurelio González, Axayácatl Campos García Rojas, Karla Xiomara Luna Mariscal, Carlos Rubio Pacho, eds., México, El Colegio de México, Centro de Estudios Lingüísticos y Literarios, pp. 105-117.

SAles Dasí, Emilio José (2004), La aventura caballeresca: epopeya y maravillas, Madrid, Centro de Estudios Cervantinos. 
